\title{
Erratum to: MEMS filter's design and modeling based on width-extensional mode plate resonator for wireless applications
}

\author{
Achraf Ben Amar $^{1} \cdot$ Dorra Bahloul $^{1} \cdot$ François Gagnon $^{1} \cdot$ Ammar B. Kouki $^{1}$
}

Published online: 8 May 2015

(C) Springer-Verlag Berlin Heidelberg 2015

\section{Erratum to: Microsyst Technol \\ DOI 10.1007/s00542-015-2488-5}

In the original publication of the article, the corresponding author's name was incorrectly spelled in the author group. The correct name should read as "Achraf Ben Amar". 